\title{
NOTAS CRÍTICAS PARA HABITAR Y TRANSFORMAR EL DISPOSITIVO URBANO
}

Critical Notes for Inhabiting and Transforming the Urban Device

\section{Luis Serrano \\ Grupo de investigación-acción interdisciplinaria en arte y entorno [GIAE _ ]/FAD/UNAM, México.}

\section{RESUMEN:}

Las ciudades se han constituido y reconstituido en un proceso dinámico complejo. A lo largo del siglo xx y principios del siglo xxi de forma hiperacelerada. Ese proceso incide en las formas de vida humana y las formas de vida humana determinan a su vez los procesos de aceleración urbana y sus implicaciones en los ecosistemas. Tanto la complejidad del tramado de acciones asociadas a lo urbano, como la hegemonía de los modelos basados en las economías de mercado, cuyo principal rasgo es sobreconsumo de energías y materias, resultan en un estado de afectación a la tierra sin precedente. Desde la propuesta de los modelos elementales de oposición campo-ciudad (Echeverría) y el concepto de economías-mundo (Braudel) retomado por el propio Echeverría, en este artículo se realiza una aproximación a la ciudad contemporánea como dispositivo específico y propio de la actual economía-mundo globalizada dominante. En ella se concentran también las múltiples posibilidades de reorganización social que apuntan a otras formas creativas y colectivas de hacer y pensar la ciudad, que pueden ser apoyadas y aceleradas por prácticas artísticas abiertas que no participen de la obtención de rentas de monopolio (Harvey), forma inherente a los mecanismos neoliberales de reproducción urbana.

Palabras Clave: proceso urbano, arte, conocimiento, economías mundo, oposición campo-ciudad, dispositivo moderno. 


\section{RESUM:}

Les ciutats s'han constituït i reconstituït en un procés dinàmic complex. $\mathrm{Al}$ llarg del segle xx i principis del segle xxi de forma hiperaccelerada. Aquest procés incideix en les formes de vida humana i les formes de vida humana determinen al seu torn els processos d'acceleració urbana i les seues implicacions en els ecosistemes. Tant la complexitat del tramat d'accions associades a l'urbà, com ara l'hegemonia dels models basats en les economies de mercat, el principal tret de les quals és el sobreconsum d'energies i matèries, resulten en un estat d'afectació a la terra sense precedent. Des de la proposta dels models elementals d'oposició camp-ciutat (Echeverría) i el concepte d'economies-món (Braudel) reprès pel mateix Echeverría, en aquest article es realitza una aproximació a la ciutat contemporània com a dispositiu específic i propi de l'actual economia-món globalitzada dominant. En aquesta es concentren també les múltiples possibilitats de reorganització social que apunten altres formes creatives i col-lectives de fer i pensar la ciutat, que poden ser recolzades $\mathrm{i}$ accelerades per pràctiques artístiques obertes que no participen de l'obtenció de rendes de monopoli (Harvey), forma inherent als mecanismes neoliberals de reproducció urbana.

Paraules clau: procés urbà, art, coneixement, economies món, oposició camp-ciutat, dispositiu modern.

ABSTRACT: Cities have always been constituted and reconstituted in a dynamic and complex process. Throughout the twentieth century and the beginnings of the twenty-first century this process has been one of hyperacceleration, affecting the ways people live, which in turn determine the processes of urban acceleration and their implications for ecosystems. The complexity of the web of actions associated with the urban, together with the hegemony of market economy models based on the overconsumption of energy and materials, have led to unprecedented effects on the earth. From the proposal of the basic models of rural-urban opposition (Echeverría) and the concept of world-economies [économie-monde] (Braudel) taken up by Echeverria, this article approaches the contemporary city as a specific device pertaining to the current dominant globalised world economy. The city is also the focus for the multiple possibilities of social reorganisation exploring other creative and collective ways of making and thinking the city, 
which can be supported and accelerated by open artistic practices that do not participate in the acquisition of monopoly rents (Harvey) inherent to the neoliberal mechanisms of urban reproduction.

KEYWORDs: urban process, art, knowledge, world-economies, rural-urban opposition modern device.

a ciudad, pero más bien lo urbano, como forma espacio temporal de producción material y simbólica puede ser entendido como un sistema adaptativo complejo y también como un dispositivo social que gestiona interacciones de diversos órdenes, y que han correspondido históricamente a mecanismos precisos de relaciones circunscritas a las condiciones de su desarrollo en partes específicas del planeta (Echeverría, 2014). Para Bolívar Echeverría existen tres modelos elementales que articularán progresivamente las ciudades contemporáneas, y desde esos modelos y la noción de renta tecnológica le es posible explicar la naturaleza específica de las ciudades contemporáneas latinoamericanas.

Las ciudades se han constituido y reconstituido en una serie de procesos dinámicos complejos. Esos procesos han incidido en las formas de habitar y las formas de habitar determinan a su vez los procesos de aceleración urbana y sus implicaciones en los ecosistemas. Tanto la complejidad del tramado de acciones asociadas a lo urbano, como la hegemonía de los modelos basados de las economías de mercado, cuyo principal rasgo es sobreconsumo de energías y materias por individuos no solidarios, no responsables, pero fundamentalmente no conscientes de las implicaciones colectivas de ese tramado de acciones, resultan en un estado de afectación a la tierra sin precedente.

En este artículo se realiza una aproximación a la idea de dispositivo urbano como producto de un proceso histórico complejo. En ese proceso la relación estrecha entre conocimiento y acción juega un papel determinante. Es claro también que son distintas las necesidades de conocimiento entre quienes buscan la reproducción de los mecanismos de acumulación de riqueza, y entre quienes buscan comprender, enunciar y poner en acción formas crí- 
ticas y alternas a dichos mecanismos. Sin embargo, las formas de detención del poder, implican también la detención o apropiación de conocimientos en formas específicas de transmisión/re-producción. En este marco contextual, ¿qué papel juegan o pueden jugar en ello las prácticas artísticas contemporáneas cuyo eje de desplazamiento se inclina cada vez más hacia ejercicios con clara y a veces decisiva implicación urbana?

Para Enrique Leff la crisis ambiental es una crisis del conocimiento. Es lo concreto de las expresiones de la crisis ambiental contemporánea lo que ha detonado la emergencia de múltiples reacciones a las formas hegemónicas de racionalidad instrumental. Estas formas asociadas a la lógica de desarrollo moderno y a la objetivación fragmentaria de la realidad han supuesto la profundización especializada y fragmentaria del conocimiento, y asociado a ello han supuesto también la aceleración en forma exponencial de procesos de producción en perspectivas lineales (Jiliberto, 2001) en conjunto con la urbanización devastadora de ecosistemas, los impactos multiefecto y multidimensión, la polarización entre concentración y escasez de recursos, la enorme acumulación de capital en pocos individuos. En contraparte, existen múltiples reacciones también generadas de forma exponencial paralelamente a la escalada de afectaciones ambientales que son portadoras del conocimiento generado a través del habitar cotidiano en el marco de un enfrentamiento de mundos y visiones. La distancia entre ellos está relacionada con las formas en que el conocimiento es derivado en acciones sobre la tierra. A su vez esas acciones constituidas en ambiente configuran el espacio de conocimiento posible a partir del cual se reproducen los distintos modos de habitar en ella.

Sin embargo, la hegemonía de las formas de pensamiento asociadas a la reproducción de la modernidad capitalista ha encontrado su punto de quiebre y sus limitaciones se han evidenciado a sí mismas a través de sus crecientes impactos, detonando la crisis ambiental. Estas formas hegemónicas se responden a sí mismas con la lógica del desarrollo sostenible y las economías verdes, sin alterar sustancialmente los procesos de producción, basadas en 
perspectivas lineales e instrumentales que les permiten proyectar el control sobre los procesos y por supuesto proyectar los márgenes de ganancia. Un ejemplo de ello es la integración de la agenda del Foro de Innovación Sostenible en el marco de la conferencia de las partes [COP] que se celebra anualmente, por representantes del gobierno y representantes de las principales compañías patrocinadoras. ${ }^{1}$ Las ciudades contemporáneas reflejan de manera inequívoca tales perspectivas de pensamiento y tales mecanismos de reproducción, convirtiendo el resto del planeta en un apéndice urbano, que requiere tutela y financiación, según la previa negociación de los planes de «las partes».

Dentro de las múltiples reacciones a dichas perspectivas hegemónicas, la respuesta teórica de Leff a esta crisis ambiental es el saber ambiental, inscrito en su epistemología ambiental. El saber ambiental es para él un cuestionamiento sobre las condiciones ecológicas de la sustentabilidad [sostenibilidad] y las bases sociales de la democracia y la justicia, una construcción y comunicación de saberes que pone en tela de juicio las estrategias de poder y los efectos de dominación que se generan a través de formas de detención, apropiación y transmisión de conocimientos (Leff, 2000).

Para Leff, como parte del proceso histórico de construcción del conocimiento humano, el pensamiento complejo surge de una perspectiva de entendimiento de la realidad no desligada del mismo proceso que construye la realidad. Donde el proceso social humano se entiende también como parte del proceso de acercamiento/distanciamiento a la comprensión de la realidad.

Leff sostiene lo anterior haciendo un recorrido histórico partiendo de la afirmación de que el pensamiento dialéctico fue una producción temprana en la historia de las ideas donde las dualidades antitéticas, la negación y la contradicción dialéctica están en la raíz de sus derivaciones ontológicas, metodológicas y epistemológicas. Leff describe el marco histórico del pensamiento que le permite dar paso a la enunciación del emergente saber ambiental.

El recorrido de Leff señala que la teoría social se dividió en dos campos: una teoría crítica y un acercamiento empírico-analítico-positivista de la realidad. Y que en el proceso de esa división, la dialéctica se convirtió en

1. $\quad<$ http://www.cop21paris.org/sponsors-and-partners/sponsors $>$. 
la piedra de toque del racionalismo crítico y aunque el pensamiento dialéctico ofrece principios generales para entender la transformación de lo real debe haber una correspondencia entre [el] pensamiento y el movimiento de los procesos materiales. Marx aporta la concepción de lo concreto del concepto - la articulación de múltiples determinaciones que hace la realidad inteligible al pensamiento - y también la idea de la dialéctica en la contradicción social, desde donde Marx puede ser considerado como precursor del pensamiento sistémico cuando piensa al hombre no desde una pretendida esencia, sino desde su contexto histórico y desde sus relaciones sociales, con lo cual, pudo revertir el idealismo dialéctico de Hegel y fundar el materialismo histórico. Engels intenta establecer sin éxito el pensamiento dialéctico en la materialidad de los procesos de la naturaleza. Más tarde la categoría de totalidad es abordada con las bases del método dialéctico por Lukács, Goldmann y Kosik, quienes privilegiaron su carácter revolucionario sobre los principios de negación y contradicción. Con la instauración de la teoría de sistemas como método y una ciencia transdisciplinaria en tiempos recientes, la categoría de totalidad dejó de ser una novedad y perdió su sentido revolucionario. El estructuralismo aporta el intento de ordenación de los niveles jerárquicos y grados de contradicción de un conjunto de relaciones estructurales. Luego, el estructuralismo genético «informado por la teoría de sistemas» intenta aprehender un conjunto de contradicciones en su movimiento en el tiempo. Y la categoría de formación socioeconómica acerca al materialismo histórico desde la estructura de los medios de producción pero mantiene fuera la contradicción ecológica de la totalidad dialéctica. A partir de entonces, la emergencia de la cuestión ambiental lleva a indagar hasta qué punto las complejas interrelaciones de los conflictos socioambientales pueden entenderse como una red compleja y jerárquica de contradicciones. Por último, inscrito en el pensamiento ecológico, Bookchim busca rescatar el pensamiento dialéctico por sus rasgos comunes, sus analogías y sus compatibilidades con la evolución biológica generando una ontología organicista (Leff, 2006). Para Leff, sin embargo, aunque el pensamiento ecológico puede informar a la organización social para internalizar las condiciones ecológicas de la sustentabilidad, esto no implica que puede ofrecer la clave para entender propiamente la naturaleza o el pensamiento humano y orientar la investigación, la conciencia social y la acción política. Para Leff existe 
una clara diferencia entre los elementos de contradicción que dan sentido al pensamiento dialéctico y los métodos de la complejidad derivados de la ecología, la cibernética y el pensamiento sistémico.

La complejidad ambiental emerge para Leff en su encuentro y sus diferencias. En esta lógica se concibe la naturaleza como una entidad socialmente construida y mediada culturalmente. La racionalidad ambiental (saber ambiental) hace una crítica a las teorías de la representación y de la identidad entre las palabras y las cosas, los conceptos y lo real (Leff, 2006). Lo ideal no contradice lo material. Lo ideal se enraíza en la naturaleza a través de significados culturales y de prácticas culturales: el orden cultural aparece como un tejido de relaciones sociales de producción; al nombrar al mundo, al ordenar la naturaleza y al innovar las prácticas productivas, la cultura contribuye a la productividad sustentable de los territorios que habita. Estas entidades híbridas donde no es posible distinguir órdenes ontológicos puros prefiguran el saber ambiental, un saber que desborda al campo de las ciencias y cuestiona la racionalidad de la modernidad.

Entonces la crisis ambiental es una crisis del conocimiento; y por lo tanto la propuesta del saber ambiental devela y desentraña las estrategias de poder que se entretejen en la epistemología empirista y racionalista que confunden el ser con el ente, lo real con la realidad, el objeto empírico y el objeto de conocimiento; desenmascara las estrategias conceptuales de las teorías de sistemas y del pensamiento ecológico; establece las bases epistemológicas para la articulación teórica de las ciencias y abre el conocimiento hacia un diálogo de saberes. El saber ambiental implica para Leff una política de la diversidad y de la diferencia que critica la retórica del desarrollo sostenible y el propósito de ambientalizar las ciencias.

Del mismo modo lo concreto de la crisis ambiental detona la emergencia de adaptaciones teóricas y discursivas que permiten incorporar ajustes en una lógica que no necesariamente cambia de sentido sino de forma. Como condición de cambio [discursivo], la emergencia de planteamientos se apoyan en la evidencia y vivencia acrecentada de las contradicciones de los modelos de desarrollo vigentes. Por esto, la idea de complejidad ambiental es también expresión [discursiva] de la crisis de civilización (Leff, 2000: 8). 
En este sentido, no se puede hablar de complejidad ambiental sin hablar también del proceso de «aprender a aprender la complejidad». La construcción del saber ambiental va ligada al abordaje y comprensión de la complejidad ambiental como otra[s] construcción[es] del conocimiento de la realidad. Es decir, se trata de una pedagogía política de aprendizajes dialógicos, multiculturales y significativos para la construcción plural de sujetos y actores sociales capaces de abrir las posibilidades para la [re]creación de mundos alternativos (Leff, 2000: 3).

La complejidad ambiental [teóricamente] implica el desciframiento de las causas de esta crisis y la base de proyección de otro[s] pensamiento[s] que se aleja[n] de algún modo de la racionalidad instrumental y se acerca[n] de algún modo a cierta sensibilidad vital, menos utilitaria y más lúdica y amorosa; al mismo tiempo reconoce a los actores de estos pensamientos no como una nueva corriente hegemónica en secuencia evolutiva de la precedente, sino como una construcción diversa, tanto divergente como convergente, a la vez que la entiende de distintos modos y que dialoga para obtener lazos solidarios para la acción en nuestro contexto presente.

\section{2}

Desde el ejercicio de aproximación-comprensión-acción soportada en la perspectiva epistémica de Leff retomo el planteamiento de los modelos de oposición campo-ciudad de Bolívar Echeverría para dar cuenta de una explicación potente sobre la historia económica de las ciudades soportada en procesos concretos desarrollados de manera diferenciada en las distintas latitudes y tiempos. Dichos procesos explican el entretejido de la espacialidad y la temporalidad social a partir de la distinción del tiempo ordinario o cotidiano y el tiempo extraordinario. Donde la producción, la distribución, el cambio y el consumo corresponden al tiempo ordinario, y la fiesta, la reunión colectiva y la política al tiempo extraordinario. En el tiempo ordinario producción y consumo son momentos extremos del ciclo general de generación de riqueza social, mediados por el momento circulatorio de distribución y cambio, y proyectados sobre el territorio (Echeverría, 2014: 13). 
La construcción de los modelos que explican la génesis histórica de la ciudad hecha por Echeverría corresponde un tanto con el modo hermenéutico [desentrañador de los orígenes de la crisis civilizatoria] descrito por Leff. Yuxtapone la teoría marxista con la noción de elección civilizatoria de Braudel para trazar una explicación de la ciudad capitalista contemporánea y las formas contemporáneas de uso del espacio social, así como de la relación campo-ciudad en América Latina empleando la noción de renta tecnológica.

Echeverría sitúa los modelos elementales de oposición campo-ciudad en tres grandes territorios configuradores de economías-mundo que corresponden con lo que Braudel llama procesos de larga duración [realidades de ritmo lento], es decir, configuraciones civilizatorias cuyo cambio en el tiempo puede ser elongado en periodos sumamente amplios.

El primer modelo lo constituye la oposición aldea-campiña, y que corresponde al occidente sedentario. El segundo modelo lo constituye la oposición campamento-desierto, y que corresponde al medio oriente nómada. El tercer modelo lo constituye la oposición asentamiento-plantación, y que corresponde al oriente sedentario.

Estas formas de uso del territorio permitieron las complejas formas civilizatorias subsecuentes identificadas con tres tipos de civilización-ciudad: 1 . Occidente. Prósperas y organizadas ciudades comerciales ligadas al cristianismo románico acumuladoras de riqueza. 2. Medio oriente. Ciudades comerciales opulentas y transitorias. 3. Oriente. Sociedades hidráulicas altamente organizadas a partir de medios de producción rudimentarios e intensa fuerza de trabajo.

Estas oposiciones presentan relaciones interdependientes entre el campo y la ciudad, pero lo urbano representa el eje extraordinario que se soporta en la actividad del tiempo rutinario. La ciudad burguesa occidental precursora de la ciudad capitalista moderna presenta un dinamismo que subvierte el orden prioritario del eje rutinario-necesario, a partir del cual originalmente orbitaba el eje extraordinario. El momento político, el momento para la concentración de la producción simbólica y la reproducción social comunitaria se concentra, determina y atrae los procesos productivos y de consumo hacia la ciudad acumuladora de riqueza. 
La constitución de la ciudad burguesa a partir de la oposición urbano-rural configurada como aldea-campiña acontece cuando el momento político religioso se junta con el momento productivo-consuntivo. Éste es un fenómeno potenciador de primer orden del proceso de reproducción de la riqueza social. Aparece entonces la llamada «autonomía citadina». Las ciudades son capaces de darse a sí mismas sus propias leyes y de controlar y ejercer autoridad sobre el territorio del cual ellas son centro. (Echeverría, 2014: 55)

En la consolidación de los distintos proyectos de capitalismo participa la ciudad occidental como una forma que absorbe procesos de las distintas economías-mundo. Entendiendo lo anterior es posible pensar que la ciudad capitalista se consolida territorialmente y hace coincidir los momentos epistémicos de su concentrada producción simbólica con las arquitecturas y urbanismos derivados de las racionalidades hegemónicas.

Las economías-mundo están basadas en su coherencia interna, propia de la concatenación de acciones, circunstancias y acontecimientos. Desde esa perspectiva Echeverría señala el papel determinante que para Braudel juega Europa en la potenciación y aceleración del proceso urbano en paralelo a la propia historia del capitalismo. Es el constante enfrentamiento entre las ciudades-estado del norte y del sur europeo el que configura el motor de expansión, crecimiento y aceleración en ese proceso histórico marcadamente distinto comparado con el resto del mundo, en la cual se integra un enorme fluir de mercancías, de dinero, de humanos, de fuerzas de trabajo (Echeverría, 2014: 71-72). Así, para Braudel la historia del capitalismo es la historia de una economía mundo que gesta dentro de sí misma un dinamismo incontenible y adopta formas muy diferentes abriéndose hacia otras economías-mundo e imponiendo al resto del planeta condiciones de existencia que lo dinamizan irreversiblemente (Echeverría, 2014: 73). A partir de todo ello, la aparición de la gran ciudad y la metrópoli supone la subordinación del campo a ellas como apéndice de la periferia industrial.

Desde siempre, las ciudades han brotado de la concentración geográfica y social de un excedente en la producción. La urbanización ha sido siempre [...] un fenómeno relacionado con la división de clases, ya que ese excedente se extraía de algún sitio y de alguien, mientras que el control sobre su uso solía corresponder a unos pocos. Esta situación general persiste bajo el capitalismo, evidentemente, pero en este caso se ve sometida a una dinámica bastante dife- 
rente. El capitalismo descansa, como nos explicaba Marx, sobre la búsqueda perpetua de plusvalor (beneficio -[ganancia]), cuyo logro exige a los capitalistas producir un excedente, lo que significa que el capitalismo produce continuamente el excedente requerido por la urbanización. Pero también cumple la relación inversa: el capitalismo necesita la urbanización para absorber el sobreproducto que genera continuamente [el propio proceso urbanizador]. De ahí surge la conexión íntima entre el desarrollo del capitalismo y el proceso de urbanización. No puede sorprendernos, por tanto, que la curva logística del crecimiento con el tiempo del producto capitalista sea prácticamente idéntica a la de la urbanización de la población mundial. (Harvey, 2013: 21)

Para David Harvey los mecanismos que, a su juicio, constituyen la base de la estrecha relación entre acumulación de capital y proceso urbano se articulan a través de un tramado bastante complejo, pero no incomprensible, donde gran parte del valor y el plusvalor creados en la producción es absorbido y desviado, pasando por todo tipo de vías complicadas, que se soportan no sólo en la creación de excedente a partir de la explotación en los procesos de producción, sino también, a través de la puesta en juego [especulación] del capital ficticio y una concomitante cadena de acciones traducidas en lo que él llama acumulación por desposesión (Harvey, 2013). En este sentido, las operaciones de acumulación por desposesión se concentran en la extracción de renta [por parte del capitalista] a partir de la apropiación de los bienes comunes generados colectivamente en las ciudades. Y que podría también explicar otras formas de despojo a partir de la dependencia desvalorizada del capital a la renta de la tierra [Marx] y la emergencia de la renta tecnológica, en el caso particular de las urbes situadas en el sur. Grandes aglomerados urbanos conocidos como megaciudades o postciudades características de las economías emergentes. Megalópolis de sustentabilidad precaria, funcionalmente desarticuladas, caóticas, polarizadas dentro de una mancha urbana entre pobre y miserable, dotadas de una infraestructura mínima junto a la que se abren deslumbrantes islotes de abundancia y desarrollo técnico (Echeverría, 2014: 79). 
Un dispositivo conceptual/factual extremadamente poderoso llamado modernidad tiene como expresión concomitante el dispositivo ciudad. Para Bruno Latour el origen de la modernidad se gesta en el enfrentamiento y posterior negociación de parcelas de influencia entre la ciencia ocupada del conocimiento acerca de las cosas y la política ocupada del conocimiento y gestión de los asuntos de los hombres. Esta negociación primaria [que Latour expone y ejemplifica en la negociación Boyle/Hobbes] de separación tajante pero complementaria, constituye así la relación entre conocimiento y acción del dispositivo moderno, articulando ciertos acuerdos y ciertas garantías que posibilitan prácticamente su «infinita» reproducción (Latour, 2007).

La primera garantía desde el territorio de la ciencia: «Aunque no construyamos la naturaleza es como si la construyéramos». La segunda desde el territorio de la política: «Aunque no construyamos la sociedad, es como si la construyéramos». Garantías aparentemente simétricas y no contradictorias. Es la tercer garantía, «la naturaleza y la sociedad deben ser absolutamente distintas», la que las aleja entre sí haciendo de ellas dos asimetrías contradictorias ocultadas por el cambio de escala que ellas mismas posibilitan; es decir, el trabajo de purificación debe permanecer absolutamente distinto del trabajo de mediación ${ }^{2}$ en el cual:

Van a poder intervenir a la naturaleza desde todo punto de vista en la fábrica de sus sociedades, sin por ello dejar de atribuirle su trascendencia radical; van a poder convertirse en los únicos actores de su propio destino político, sin por ello dejar de sostener su sociedad por la movilización de la naturaleza. Por un lado, la trascendencia de la naturaleza no impedirá su inmanencia social; por el otro, la inmanencia de lo social no impedirá que el Leviatán siga siendo trascendente. (Latour, 2006: 59)

Una construcción bastante bella, dice Latour, que permite hacerlo todo sin estar limitado por nada. Un potente dispositivo moderno completado por la cuarta garantía constituida por el Dios tachado. Un Dios ausente y a la vez

2. Purificación entendida como la operación de separación tajante entre naturaleza y sociedad. Mediación entendida como las operaciones de híbridos conectores de dimensiones sociales, naturales y espirituales (Latour, 2007). 
disponible. Posición ideal puesta dos veces entre paréntesis. La primera vez en la metafísica y la segunda vez en la espiritualidad (Latour, 2007: 61). El punto esencial de esta constitución moderna, dice Latour, es volver invisible, impensable, irrepresentable el trabajo de mediación que reúne a los híbridos. Sin embargo, permite la proliferación multiplicada de éstos al mismo tiempo que niega su posibilidad y su existencia.

Tres veces la trascendencia y tres veces la inmanencia en un cuadro cruzado que clausura todas las posibilidades. No hicimos la naturaleza; hacemos la sociedad; hacemos la naturaleza [en el laboratorio]; no hicimos la sociedad; no hicimos ni una ni otra, Dios lo hizo todo; Dios no hizo nada, nosotros lo hicimos todo. No se comprende nada de los modernos si no se ve que las cuatro garantías se sirven una a otra de checks and balances. (Latour, 2007: 61)

Dispositivo móvil en el tiempo y en el espacio que configura la base simbólico-material de intercambios que genera las ciudades capitalistas apoyadas por la poderosa crítica moderna que argumenta a favor de cada operación de purificación mientras regula la proliferación multiplicada de los híbridos de los cuales se nutre. Las relaciones de poder necesarias para la reproducción del dispositivo capitalista moderno pueden explicarse a su vez a partir del señalamiento de Manuel Castells.

El poder es la capacidad relacional que permite a un actor social influir de forma asimétrica ${ }^{3}$ en las decisiones de otros actores sociales de modo que se favorezcan la voluntad, los intereses y los valores del actor que tiene el poder. (Castells, 2012: 33)

Capacidad relacional mediada necesariamente por dispositivos. Para Castells el poder no es un atributo, es una relación. Las relaciones de poder implican la participación de al menos dos implicados en dicha relación. La asimetría en las relaciones de poder se constituye así por el despliegue de dispositivos de comunicación/persuasión incidentes en las prácticas, en los acuerdos [también asimétricos], y en la reproducción cultural de las formas de purificación, potenciadas por la crítica, y de mediación, toleradas pero negadas sus prácticas y sus argumentos [siempre marginales/marginados]. Y

3. Asimetría distinta a la planteada por Latour como oposición a la simetría perfecta del dispositivo de las 4 garantías. 
por supuesto por el despliegue de dispositivos espaciales que permiten o no el despliegue y desarrollo de ciertas prácticas y ciertos modos de habitar. Y en esa misma medida, ciertos modos de comprender y experimentar la realidad.

Félix Duque rastrea principios de separación/disyunción desde la Grecia antigua. Para Duque la idea de naturaleza es un recurso ingenioso del pensamiento griego para delimitar el ámbito de lo humano frente a lo otro no humano. Esa otredad que configura posibilidades de separación y contra-explicación fuera del marco del bien engranado dispositivo moderno. Desmenuzando desde la etimología y la filosofía la noción castellana de medio ambiente, Duque advierte en ello una astucia de la racionalidad moderna. Medio [medium], como algo en lo que los hombres y las cosas está inmersos. En ese medio los hombres circunspectan; introyectan aquello de lo que dependen, y por tanto importa. Ambiente [de ambio], «el que circunda y abarca algo con la vista»; de ahí ámbito, terreno o campo abarcado; y también ambición. Homo ambiens o ambitius, aquel que «anda alrededor de una cosa, que la abraza, la enlaza, la rodea». El hombre es a su vez centro de su esfera de acción y abarcador de su ámbito. Duque cita a un Schiller describiendo esta astuta apropiación de la naturaleza:

De ser esclavo de la naturaleza mientras se limita a sentirla, pasa el hombre a ser su legislador tan pronto la piensa. Ella que, en cuanto poder, antes lo dominaba, está ahora ahí plantada, en cuanto objeto, ante la mirada enjuiciadora de aquél. (Duque, 2008: 9)

La naturaleza así surge a partir de la emergencia de lo técnico y lo urbano arquitectónico como expulsión respecto de este ámbito puramente humano (Duque, 2008: 13).

La analogía, ya repasada por muchos, entre habitar-pensar-construir explica inicialmente procesos miméticos de distintos momentos de la praxis humana en relación con su medio y con su ambiente. Es decir, procesos miméticos en su forma de aproximación a, en y desde sí y lo expulsado de sí, su propia explicación/separación/acción hacia, en y desde de lo otro. En la relación del urbanismo [y la arquitectura] con aspectos de complejidad ambiental la analogía entre el construir, el habitar y el pensar resulta útil para pensar relacionalmente los planos conceptual, procedimental y espacial de la praxis transformadora del espacio. Mismo esquema que coincide 
con el planteamiento de la interrelación entre paisaje interior [construido] y paisaje exterior [construido] (Danserau, 1981), que a su vez coincide con el planteamiento de la epistemología genética de los sistemas complejos (García, 2006).

Para construir es necesario espaciar, para espaciar es necesario pensar, para pensar es necesario habitar, para habitar no es siempre necesario construir en el sentido común del término. Sin embargo, para las formas específicas derivadas de la progresión y asimilación conjunta de las economías-mundo precedentes en una globalización económica con pretensiones uniformes, son necesarios dispositivos constructivos bien específicos.

No todos habitamos las ciudades del mismo modo y desde las mismas condiciones de experiencia, conocimiento y acceso. Construir, pensar y habitar el dispositivo moderno de las ciudades capitalistas a través de las magistralmente articuladas relaciones de poder asimétricas puede a su vez experimentarse en la propia modernidad capitalista desde distintos ethos, bien en la modernidad capitalista, o bien para la modernidad capitalista (Echeverría). ${ }^{4}$ He aquí la cuestión. ¿Qué papel juegan o pueden jugar en ello las prácticas artísticas contemporáneas cuyo eje de desplazamiento se inclina cada vez más hacia ejercicios con clara y, en ocasiones, decisiva implicación urbana? ¿Desde qué ethos? según lo que ha sugerido Echeverría. Por supuesto, las prácticas artísticas contemporáneas responden de maneras diferenciadas, y juegan también un papel diferenciado según los distintos tipos de asociaciones que cada una establece. Sin embargo, parece haber una serie de definiciones bastante planas acerca de las prácticas artísticas contemporáneas [educativas, participativas, colaborativas, activistas, situadas, contextualiazadas, socialmente comprometidas] como si todas ellas constituyeran un solo bloque de prácticas activas en un proceso urbano unidireccional. Esto habrá que analizarlo a detalle en otra oportunidad.

4. $\quad<$ http://www.analectica.org/articulos/garcia-ethos/>. 
Las prácticas artísticas contemporáneas abrevan de una larga tradición de ejercicios críticos. Particularmente abrevan del ejercicio crítico continuado de las vanguardias del siglo xx hacia las perspectivas hegemónicas del pensamiento y la acción política. Pero también abrevan de todas las formas que, una vez sometidas las vanguardias, se instrumentaron de maneras contradictorias como ejercicios libertarios, ahora ya con la institución artística como foco de su crítica.

Así, en las décadas recientes los trabajos en el campo del arte contemporáneo se han caracterizado por situar su [obra] crítica en las instituciones, particularmente en las instituciones del propio campo del arte. Históricamente se reconocen tres momentos claramente diferenciados de esta crítica institucional (Holmes, 2010). Se trata de un ejercicio continuo de auto-reflexividad con distintos grados de contradicción y paradoja ontológica.

El primer momento situado en las décadas de los sesenta y setenta caracterizado por los lances minimalistas y conceptuales centrados en la crítica del espacio instituido para el arte, el espacio estético especializado, materializado en el cubo blanco de galerías y salas de museo.

El segundo momento situado en las décadas de los ochenta y noventa caracterizado por una crítica a la lógica objetivista ${ }^{5}$ del museo y su relación con el poder, ligado fuertemente a perspectivas feministas y postcoloniales. Esta crítica se centró en el análisis meta y auto-reflexivo de las representaciones en el propio espacio instituido, una crítica del funcionamiento de la critica en el propio espacio criticado. Una serpiente que muerde su cola. Es decir, un arte, dentro del espacio del arte, centrado en la crítica de los mecanismos opresivos que implícita o explícitamente habían sido previamente convenidos al emplear el propio espacio instituido como plataforma de la crítica.

El tercer momento, actual y vigente, generado desde la marginalidad del campo, es decir, no principalmente en los procesos del mainstream artístico global, sino en el linde institucional, con naturales y fuertes nexos con las prácticas culturales mediadas por los procesos de precarización del trabajo, la

5. Lo otro como objeto de contemplación y consumo (Holmes, 2010). 
incesante embestida neoliberal y los mecanismos de resistencia cotidiana a lo largo y ancho del planeta. Las posiciones asumidas en este tercer momento no son, por supuesto, ni uniformes, ni estables.

Asistimos probablemente entonces a un cambio epocal en el campo del arte, así como asistimos a un cambio epocal en el terreno social. La inoperante permanencia de las lógicas ligadas a la autonomía del arte en los diversos y complejos contextos sociales ha obligado a diversas adecuaciones por parte de los variopintos actores del campo del arte. Particularmente entre quienes se ven implicados en el pensamiento y promoción de la praxis artística, pues el mercado del arte se adapta también pero sin graves complicaciones. Por un lado, el arte sigue siendo un recurso no agotado que posibilita inversiones desreguladas y de gran plusvalía. No obstante, y quizá en apoyo a las muy cercanas lógicas del mercado, los museos y centros culturales centran sus estrategias en los departamentos educativos y de formación de públicos; esto es, formación para la comprensión de los relatos complejos generados en el linde del campo. Y por otro lado, pero tampoco muy lejano, buena parte de los artistas centran sus tácticas en la supervivencia cotidiana ${ }^{6}$ y el desmarcamiento crítico de las lógicas institucionales que los acerca a problemáticas comunes con otros actores sociales.

Sin embargo, este desmarcamiento crítico, tampoco exento de contradicciones y que se desarrolla en el marco de una flexibilización cada vez más acentuada de la recepción de las lógicas de control institucional, difícilmente escapa, a su vez, de las lógicas estéticas de la vida cotidiana portadoras de los propios instrumentos y mecanismos de ocultamiento y control. Si históricamente, desde el arte, la crítica institucional ha acompañado también a los movimientos sociales críticos casi por definición, su condición de dependencia institucional [vía legitimaciones, visibilizaciones, dispositivos, formatos, espacios o presupuestos] y conceptual [vía nociones circulantes hegemónicas] lo acerca también a mecanismos alienados de reproducción pragmática concordantes con la flexibilización de condiciones de trabajo a las que obliga el statu quo neoliberal.

6. Que los obliga a trabajar en el marco de proyectos institucionales en condiciones de precariedad. 
Ahora bien, si como explica Harvey, la cultura es un bien común y es innegable que se ha convertido en una especie de mercancía, y que también, persiste la creencia de que en ciertos productos y acontecimientos culturales hay «algo especial» que lo distingue, «cada vez más porosamente», de las mercancías producidas y consumidas en masa. Esta percepción ligada a las condiciones que institucionalmente se plantean para la apreciación, lectura, debate o mero consumo de la producción artística son las mismas heredadas de la lógica contemplativa del espectador culto y con buen gusto, construida por la racionalidad burguesa europea en el siglo XVIII. Si en la ciencia se reconoce la existencia perniciosa de una doxa científica, en el arte del presente resulta apabullante la existencia de una doxa artística tan arraigada como inadvertida, dado que este soporte heredado desde una tradición teóricamente deshabilitada configura casi invariablemente los soportes de la producción artística, incluso la más crítica. Esta invisibilidad del dispositivo artístico contemporáneo oculta a su vez el papel que éste juega en la producción de rentas de monopolio, basadas en «eso» especial, «único» que ofrece un determinado bien producido individual o colectivamente. Los artistas en el mercado del arte participan directamente de las rentas de monopolio y contribuyen a la reproducción ideológica del lugar común hegemónico para la validación de las prácticas artísticas.

Pero eso que llamamos arte ha participado históricamente en la configuración de la cultura del mundo como bien común y colectivo en distintas formas de configuración económico-social. Las ciudades han sido históricamente producto de la aplicación de excedentes de la acumulación de riqueza a formas materiales que constituyen nuestros hábitats y formas inmateriales que constituyen nuestros legados culturales. Todos ellos producidos desde las relaciones complejas en distintas formas de configuración de tiempos ordinarios y extraordinarios. Tiempos que en la contemporaneidad se atomizan en múltiples formas diferenciadas, pero en el mismo marco de la lucha de clases; donde el 1\% de la población mundial decide desde el control de los dispositivos urbanos, frente a las múltiples e inconmensurables formas de articular la vida cotidiana de un $99 \%$ que aún no descifra las claves para su desarticulación y reconfiguración. 
Si, como dice Harvey, la forma capitalista de urbanización está tan plenamente inserta en la reproducción del capitalismo y resulta fundamental para ésta, eso significaría también que para cualquier intento de poner en pie una alternativa anticapitalista sería decisivo hallar formas alternativas de urbanización, o bien, formas alternas de reconfigurar las asimétricas distribuciones de tiempos ordinarios y extraordinarios en el espacio planetario.

Entonces, si la hegemonía de las formas de pensamiento asociadas a la reproducción de la modernidad capitalista han encontrado su punto de quiebre y sus limitaciones se han evidenciado a sí mismas a través de sus crecientes impactos, llevando a límites no conocidos la crisis ambiental, ¿no acaso habría que articular esas poderosas formas críticas del arte en espacios de diálogo y reconfiguración de nuestras formas de entendimiento, explicación y acción política con esas otras poderosas formas críticas de las ciencias y las humanidades que nos muestran en conjunto la imperiosa necesidad de pensar, construir y habitar otro tipo de ciudad?, y ¿no estamos acaso en posibilidad de articular reflexiones complejas desde todos los campos de conocimiento para diseñar un[os] dispositivo[s] que desarticule[n] la capacidad de re-producción de las acumulaciones absurdas de capital a partir del reconocimiento y reclamo de nuestra participación en la producción colectiva de los bienes comunes de la ciudad?

\section{Referencias}

Castells, M. (2012): Comunicación y poder, Siglo xxi, México.

Danserau, P. (1981): Interioridad y medio ambiente, Nueva Imagen, México.

DuQue, F. (2001): Arte público y espacio político, Akal, Madrid.

ECHEVERría, B. (2014): Modelos elementales de la oposición campo-ciudad: Anotaciones a partir de una lectura de Braudel y Marx, Ítaca, México.

García, R. (2006): Sistemas complejos: Conceptos, método y fundamentación epistemológica de la investigación interdisciplinaria, Gedisa, Barcelona.

Harvey, D. (2013): Ciudades rebeldes: Del derecho a la ciudad a la revolución urbana, Akal, Madrid. 
Holmes, B. (2010): «Investigaciones extradisciplinares. Hacia una nueva crítica de las instituciones», en Producción cultural y prácticas instituyentes: Lineas de ruptura en la crítica institucional, Traficantes de sueños, Madrid.

LATOUR, B. (2007): Nunca fuimos modernos: Ensayo de antropología asimétrica, Siglo XXI, Buenos Aires.

LefF, E. (coord.) (2000): La complejidad ambiental, Siglo XxI, México.

- (2006): Aventuras de la epistemología ambiental, Siglo XXI, México.

JiliberTo, R. (2001): «Infructuosidad, intuición y reduccionismo: Fundamentos para una economía ecosistémica», en Polis \#1, Sociedad, universidad y conocimiento, en línea. Disponible en: $<\underline{\text { https://polis. }}$ revues.org/8152>. 